\title{
Park Characteristics Influences to Physical Activity among Overweight Adolescents
}

\author{
Ajau Danis ${ }^{a}$, Suriati Sidek ${ }^{a}$, Safiah Md. Yusof ${ }^{b}$ \\ a Basic Science Department, Faculty of Health Sciences \\ b Nutrition and Dietetic Department, Faculty of Health Sciences \\ UiTM, 42300 Puncak Alam, Selangor, Malaysia \\ ajaudanis@puncakalam.uitm.edu.my
}

\begin{abstract}
The link between environmental characteristics of neighbourhood parks and adolescents' physical activity is poorly understood. Therefore, the present study aims to explore the environmental characteristics of the neighbourhood parks that influence physical activity from the perception of overweight adolescents. In-depth semi-structured interviews with 20 overweight adolescents between 13 and 17 years old successfully done. Interviews recorded, transcribed and analyzed based on a thematic content analysis. The results showed that physical and social environment influenced physical activity and neighbourhood parks usage. It is essential to consider these environmental characteristics in developing physical activity intervention that aims to promote physical activity among overweight adolescents.
\end{abstract}

Keywords: Environmental characteristics; neighbourhood park; overweight adolescent; physical activity

eISSN: 2398-4279 @ 2016. The Authors. Published for AMER ABRA by e-International Publishing House, Ltd., UK.. This is an open access article under the CC BY-NC-ND license (http://creativecommons.org/licenses/by-ncnd/4.0/). Peer-review under responsibility of AMER (Association of Malaysian Environment-Behaviour Researchers), ABRA (Association of Behavioural Researchers on Asians) and cE-Bs (Centre for EnvironmentBehaviour Studies), Faculty of Architecture, Planning \& Surveying, Universiti Teknologi MARA, Malaysia.

https://doi.org/10.21834/ajqol.v1i2.26 


\subsection{Introduction}

Data suggest that approximately $30 \%$ of Malaysians 18 years and older are currently overweight (Malaysia National Health and Morbidity Survey Volume II, 2011). The prevalence is higher than it was in 1996 (Rampal et al., 2007) and continues to be a national public health threat. Also, the Malaysia National Health and Morbidity Survey Volume II (2011) also found that the prevalence of obesity is higher in urban areas than in rural areas. This finding is consistent with the physical activity levels; the urban population had a lower level of physical activity (63.2\%) than the rural population (67.2\%). Based on this prevalence, it may appear that people in urban areas are more likely to be obese and are less likely to participate in physical activity.

Although previous studies have suggested that the lifestyle transition and changes in the dietary patterns of Malaysians may contribute to the development of overweight and obesity (Pon et al., 2004), Hills et al. (2011) revealed that low levels of physical activity may also be one of the factors. Recommended physical activity for young people aged 5-17 years includes play, games, sports, recreation and exercise (World Health Organization, 2010). Performing regular physical activity is a healthy way to decrease the risk of chronic and non-communicable diseases (Aniza and Fairuz, 2009; Sarwer and Dilks, 2012; Shukur et al., 2010; World Health Organization, 2010) and may reduce the risk of obesity (Hills et al., 2011). This possibility highlights the importance of efforts to increase and encourage physical activity among overweight adolescents so that they can reduce their weight and have a better quality of life in return.

\subsection{Literature Review}

Over the last decade, the association between physical activity and environmental characteristics has become a topic of interest in public health research. People would like to engage in physical activity in recreational areas, such as neighbourhood parks, public parks, sports complexes and community parks (Cohen et al., 2006; Floyd et al., 2011). Thus, it is essential to create venues that are conducive to physical activity in residential areas to encourage physical activity (Shukur, 2010). Neighbourhood parks are the most common venue for physical activity, and residents can assess them at no cost. Several factors have been identified that influence the use of neighbourhood parks for physical activity such as environmental characteristics, individual characteristics and social characteristics (Loukaitou-Sideris, 2004; Ries et al., 2008). However, the influence of environmental characteristics is an issue that is poorly understood (Humpel et al., 2002).

An environmental characteristic is defined herein as a perceived characteristic of the environment in neighbourhood parks in which adolescents engage in physical activity. According to Bedimo-Rung et al. (2005), the physical environment of the parks seems to be related to physical activity and park visitation. For example, the availability of a facility is positively associated physical activity levels (Ries et al., 2008), and in contrast, inconsistent 
facility availability may lead to less physical activity and higher obesity rates (GordonLarsen et al., 2006). The participants in a study conducted by Aniza and Fairuz (2009) reported that poor air quality, the far distance of the park and the unsafe of the jogging track were the factors that discourage them from physical activity participation. In another study, Ries et al. (2008) identified four dimensions of the environment that can affect the use of recreational facilities: physical, social, organisation and economic. They conclude that increasing facility availability may promote physical activity and decrease the risk of obesity.

Babey et al. (2008) examined the relationship between physical activity and access to parks. They found that adolescents in urban areas were more likely to be involved in regular physical activity when they have access to parks. Other studies, however, have found contradictory findings on the association between environmental characteristics and physical activity (Ferreira et al., 2007). For example, one study found no link between the proximity of the park and physical activity (Adkins, 2004), and another study found no association between neighbourhood safety and physical activity (Sallis, 1999). These inconsistent findings need further exploration. In Malaysia, such studies are still limited in the field, and much less emphasis has been placed on research specifically about overweight adolescents. Therefore, the present study was aimed to (1) explore the environmental characteristics of the neighbourhood parks that influence physical activity and (2) describe the participant's experiences in using the neighbourhood parks.

\subsection{Methodology}

The study was carried out using an exploratory qualitative study approach. As little is known about the environmental characteristics of neighbourhood park influences physical activity, a qualitative approach was considered most appropriate. The sample size for the qualitative study is flexible as according to Patton (2002), "there are no rules for sample size in a qualitative study"(pp. 244). Hence, the present study recruited twenty overweight participants as the data obtained have been saturated. The participants were selected based on the criterion purposive sampling. They included eight boys and 12 girls, aged 1317 years. The participants reside and attend school in Bandar Sri Damansara. Bandar Sri Damansara is an urban residential setting, and it has numerous neighbourhood parks.

\subsection{Ethical clearance and consent}

Approvals were obtained from the Research Ethics Committee of the Faculty of Health Sciences, Universiti Teknologi MARA, the Ministry of Education Malaysia, the state education department and the participating school. Also, consent was obtained from the parents and the participants. 


\subsection{Data collection and procedures}

The data were collected during in-depth, semi-structured interviews conducted in the Malay language. Participants were selected from a list of the names of overweight students based on data from the Standard Kecergasan Fizikal Kebangsaan (SEGAK). Those overweight participants who have been to the neighbourhood parks and consented by the parents were interviewed. The interview was conducted for approximately one hour, and it was recorded.

\subsection{Data analysis}

The data from the in-depth interviews were analysed by performing a thematic content analysis in accordance with the guidelines provided by Braun and Clarke (2006). First, the data were transcribed verbatim in the Malay language. Then, the data were translated into the English language by a language expert to ensure that the data were equivalent in meaning. Next, each transcript was read carefully and then re-read line by line to identify codes. The codes with similar content were then combined into themes. Finally, all of the authors reviewed the emerging themes to reach a consensus on the final themes.

\subsection{Results and Discussions}

Neighbourhood parks can either encourage or discourage physical activity. The present study found that participants' perception about the environmental characteristics of neighbourhood parks were fairly consistent. They identified two dimensions of environments that influenced their physical activity and park visitation; including physical and social environments. These dimensions were similar to the dimensions acknowledged by non-overweight adolescents in other studies (Aniza and Fairuz, 2009; Gordon-Larsen et al., 2006; Loukaitou-Sideris, 2004).

\subsection{Physical environment}

There were three characteristics of the physical environment that are preferred by participants; adequate facilities, aesthetics quality, and proximity of the neighbourhood park.

\subsubsection{Adequate facilities}

Most of the participants acknowledged that the lack of facilities in neighbourhood parks is the most significant characteristic that discourages them from engaging in physical activity. For example, adolescents are less likely to visit a park that offers inadequate exercise facilities. As described by this respondent, "I seldom used the neighbourhood park because, for me, the condition of the park is not suitable for physical activity. This is because the facilities are inadequate. They should provide complete and adequate facilities for exercise. I lived in a flat so, many people there wanted to use the exercise facilities" (boy, age 17 years). 
In addition to inadequate exercise facilities, some other participants explained that they were unlikely to go to the park because it lacked sports facilities. They said, "The neighbourhood park at my place has only a children's playground and a badminton court. You hardly ever see people there. I didn't go to the park because there is no basketball court. I love to play basketball!" (boy, age 16 years).

"I refuse to go to the neighbourhood park because the badminton court has been taken over by other people playing sepak takraw. The park has only one sepak takraw court. When the sepak takraw court is occupied, those people use the badminton court to play sepak takraw instead. So, I have no place to play badminton"(boy, 16 years).

The above findings show that the existing facilities in their neighbourhood parks are inadequate, and proper facilities for exercise and sports are needed. These findings complement the findings from other studies. Prins et al. (2009) found that adolescents in their study actively participated in sports when sports facilities were available and adequate in their neighbourhood. As recommended by many studies, neighbourhood parks should be equipped with various types of facilities, including sports and exercise facilities (Ries et al., 2008; Ries et al., 2009), to promote physical activity (Sakinah et al., 2012). Increasing the availability of facilities may reduce the rate of overweight (Gordon-Larsen et al., 2006). Reducing these barriers may be helpful in improving the levels of physical activity levels among adolescents (Hashim et al., 2011).

\subsubsection{Aesthetics quality}

A few participants identified certain aesthetics of neighbourhood parks that encourage them to engage in physical activity. These participants explained what they like about the aesthetic qualities of a park:

"The parks that I love most are the ones surrounded by lakes, where you can see people flying kites for fun, which have a jogging track and equipped with several shaded areas for people to get rest for a while. For example, Taman Metropolitan, Kepong. It has everything that I mentioned to you earlier. I enjoy it and love to go there to do exercise!"(boy, age 17 years).

"I like to go to Taman Metropolitan, Kepong with mum and sister for jogging. You can find a good place to exercise there. The thing I like most is that it has very nice scenery; you can feel the breeze while you jog, and it is equipped with many exercise facilities, too. It would be good if I could find a place like it in Bandar Sri Damansara so that I can say that I will go there every day"(boy, age 17 years).

"I often went to Manjalara park because it's a wide park. The size of the park is important. If the park is big, we can do anything that we want. People will not focus on you and bother you because the park is wide. The neighbourhood park nearby my home is small, and I felt like everybody was looking at me"(girl, age 13 years).

Moreover, the cleanliness has also been reported as an essential aesthetic of a park. As described by this participant, "The condition of the park in my area was disgusting. You can find trash and fallen dry leaves littered all over the park. Moreover, the park is poorly 
maintained. I don't think it is suitable for physical activity anymore. I don't like dirty settings like that!"(boy, age 17 years).

The present study shows that the aesthetic qualities of the park, such as the presence of enjoyable scenery, park-like natural elements, and a large park size may promote the use of the park for physical activity whereas the presence of trash or the general uncleanliness of a park may deter its use. This finding is supported by other studies that have suggested that the aesthetic appeal of a park may affect physical activity (Humpel et al., 2002), and incorporating natural elements into the park may attract people to visit park (Bedimo-Rung et al., 2005; Kaczynski et al., 2008; Ries et al., 2008). However, the presence of litter and the lack of cleanliness may negatively affect the aesthetics of the park (McCormack et al., 2010).

The preferred park size is different from the result of other studies. Adults in the study by Kaczynski et al. (2008) reported that their participation in physical activity was not associated with the park size. They were more likely to use parks with more attributes, such as a paved trail, unpaved trail or a wooded area, as opposed to parks of a particular size. On the other hand, the current study shows that overweight adolescents preferred a large park because they were conscious of being observed while participating in activities. They felt insecure about their appearance (Deforche et al., 2005) and about being big, which may prevent them from participating in physical activity (Ajau et al., 2014). Therefore, improving the aesthetic qualities would make the park more appealing to adolescents.

\subsubsection{Proximity}

The participants reported that having neighbourhood parks near their house would encourage them to participate in physical activity. As one participant said,

"The location of the park is quite far, so l've decided not to go"(girl, age 15 years).

Proximity to the neighbourhood park is preferred because of limited transportation. One participant said, "We have to go by car. I would prefer to have it within walking distance so I could go every day to play with friends"(girl, age 13 years).

Proximity to a neighbourhood park is also important for encouraging physical activity among adolescents. This finding was shared by other studies (Aniza and Fairuz, 2009; Cohen et al., 2006; Ries et al., 2008) that suggested that proximity might influence physical activity. It appears that adolescents are thought to have more constrained mobility than an adult because they do not possess transportation at this age (Cohen et al., 2006). Therefore, it is essential to have a neighbourhood park that is located close to home to increase the opportunities for adolescents to engage in physical activity.

\subsection{Social environment}

Neighbourhood park is the place where adolescents may fulfil their social benefit (Shukur, 2010) and a place to have fun (Ries et al., 2008). Therefore, having a safe and secure social environment in a neighbourhood park was demonstrated by participants. Some of them, particularly girls, expressed concerns about the safety and security in the 
neighbourhood park. These participants explained how safety and security issues prevent them from participating in physical activity:

"My mum didn't let me go to the park alone or even with my friends. My mum said that nowadays, the environment is different, and everyone is potentially at risk from danger"(girl, age 15 years).

"Yes, there is a park near my house, but it is a quiet park. It's like nobody was there. Very dangerous! It is surrounded by forest. I'm afraid of it. I feel that it is unsafe for us to do any physical activity there"(girl, age 13 years).

This finding aligns with the study by Ries et al. (2008). Girls' involvement in outdoor activities may be restricted because they are fearful of crime and exposure to dangerous situations. Consequently, they used parks rarely (Ries et al., 2009) and must find other ways to be physically active, such as participating in indoor activities (Bedimo-Rung et al., 2005). A safe setting is more likely to promote outdoor activity (Loukaitou-Sideris, 2007), especially for adolescents in urban areas (Babey et al., 2008). It appears that safety concerns influenced adolescents' decisions to participate in outdoor activities.

Furthermore, the participants also made some complaints about social disturbances that occurred in their neighbourhood parks. Two participants explained, "There is a park near my house, but l'm not comfortable playing there because there is a gang who likes to sit there doing nothing but smoking. I don't want to get mixed up with them. I dislike going to the park. Every time I want to go there, those people are always there, for sure. When I start to play, for instance, playing badminton, they disturb me. That is the reason why I choose to play on the school fields instead. For me, the park is no longer suitable for adolescents to perform physical activity"(boy, age 17 years).

"l'm not interested in using the park. There are people who like to loiter and do stuff like sniff glue. As a result, they were often drowsy. They stay there from noon until evening. They shouted at us while we were playing. I don't like those situations"(boy, age 17 years).

Adolescents were less likely to use neighbourhood parks where social disturbances occurred (Molnar et al., 2004). They perceived these social disturbances as a sign that gangs controlled the neighbourhood park, and they do not want to become involved. Studies have shown that the presence of undesirable park users, such as loiterers (McCormack et al., 2010), can cause social disturbances, such as drug activity. These disturbances may prevent adolescents from participating in physical activity (Ries et al., 2008) because they may cause fear (Loukaitou-Sideris, 2007) and concerns about safety (McCormack et al., 2010). These findings highlight the importance of providing adolescents with safe and secure neighbourhood parks. This goal could be achieved through neighbourhood interventions, such as park monitoring (Ries et al., 2008). As a result, physical activity may increase, which may also reduce the risk of overweight (Molnar et al., 2004). 


\subsection{Conclusion}

Overall, the present study found that the physical and social environments in neighbourhood parks influenced the physical activity participation among overweight adolescents. We hope that the environmental characteristics discussed by the adolescents in the present study can be taken into consideration. Such information is vital in developing physical activity intervention that aims to promote physical activity. Making several improvements to existing neighbourhood parks may encourage frequent neighbourhood use and increase physical activity. It is suggested that the developer equips the residential areas with healthy and pleasant neighbourhood parks so that overweight adolescents can be physically active and improve their quality of life.

There are some limitations to this study. First, the qualitative nature of the study does not allow us to generalise the findings to the population. Second, as the present study mainly exploring the perception of adolescent, future research should include direct observation of the neighbourhood park to obtain a broader perspective in identifying the environmental characteristics. The observational data may produce strong evidence to support the findings from the interviews.

\section{Acknowledgement}

Our gratitude to Universiti Teknologi MARA (UiTM) for the grant (600-RMI/DANA 5/3 $\operatorname{RIF}(401 / 2012))$ given for this research.

\section{References}

Adkins, S., Sherwood, N. E., Story, M., \& Davis, M. (2004). Physical activity among African-American Girls: The role of parents and the home environment. Obesity Research, 12 (supplement), 38S - 45S.

Ajau, D., Suriati, S., \& Safiah, M. Y. (2014). Environmental characteristics influences on physical activity among overweight adolescents in urban neighbourhood parks. Procedia-Social and Behavioral Sciences, 153, 402-409.

Aniza, I., \& Fairuz, M. R. (2009). Factors influencing physical activity level among secondary school adolescents in Petaling district, Selangor. Medical Journal of Malaysia, 64(3), 228-232.

Babey, S. H., Hastert, T. A., Yu, H., \& Brown, R. (2008). Physical activity among adolescents when do parks matter? American Journal of Preventive Medicine, 34(4), 345-348.

Bedimo-Rung, A. L., Mowen, A. J., \& Cohen, D. A. (2005). The significance of parks to physical activity and public health: a conceptual model. American Journal of Preventive Medicine, 28(2S2), 159-168.

Braun, V., \& Clarke, V. (2006) Using thematic analysis in psychology. Qualitative Research in Psychology, 3(2), 77-101. 
Cohen, D. A., Ashwood, J. S., Scott, M. M., Overton, A., Evenson, K. R., Staten, L. K., Porter, D., McKenzie, T. L., \& Catellier, D. (2006). Public parks and physical activity among adolescent girls. Pediatrics, 118(5), e1381-e1389.

Deforche, B., De Bourdeaudhuij, I., Tanghe, A., Debode, P., Hills, A. P., \& Bouckaert, J. (2005). Role of physical activity and eating behaviour in weight control after treatment in severely obese children and adolescents. Acta Paediatrica, 94(4), 464-470.

Ferreira, I., van der Horst, K., Wendel-Vos, W., Kremers, S., van Lenthe, F. J., \& Brug, J (2007). Environmental correlates of physical activity in youth—a review and update. Obesity Reviews, 8(2), 129-54.

Floyd, M. F., Bocarro, J. N., Smith, W. R., Baran, P. K., Moore, R. C., Cosco, N. G., Edwards, M. B., Suau, L. J., \& Fang, K. (2011). Park-based physical activity among children and adolescents. American Journal of Preventive Medicine, 41(3), 258-265.

Gordon-Larsen, P., Nelson, M. G., Page, P., \& Popkin, B. M. (2006). Inequality in the built environment underlies key health disparities in physical activity and obesity. Pediatrics, 117(2), 417-424.

Hashim, H. A., Golok, F., \& Ali, R. (2011). Profiles of exercise motivation, physical activity, exercise habit and academic performance in Malaysian adolescents: a cluster analysis. International Journal of Collaborative Research on Internal Medicine and Public Health, 3(6), 416-428.

Hills, A. P., Anderson, L. B., \& Byrne, N. M. (2011). Physical activity and obesity in children. British Journal of Sports Medicine, 45(11), 866-870.

Humpel, N., Owe, N., \& Leslie, E. (2002). Environmental factors associated with adult's participation in physical activity. A review. American Journal of Preventive Medicine, 22(3), 188-199.

Kaczynski, A. T., Potwarka, L. R., \& Saelens, B. E. (2008). Association of park size, distance and features with physical activity in neighbourhood parks. American Journal of Public Health, 98(8), 1451-1456.

Loukaitou-Sideris, A. (2004). Transportation, land use, and physical activity: Safety and security considerations, TRB special report 282: Does the built environment influence physical activity? Examining the evidence. Paper prepared for the Transportation Research Board and the Institute of Medicine Committee on Physical Activity, Health, Transportation, and Land Use.

McCormack, G., Rock, M., Toohey, A. M., \& Hignell, D. (2010). Characteristics of urban parks associated with park use and physical activity: A review of qualitative research. Health and Place, 16(4), 712-726.

Molnar, B. E., Gortmaker, S. L., Bull, F. C., \& Bika, S. L. (2004). Unsafe to play? Neighborhood disorder and lack of safety predict reduced physical activity among urban children and adolescents. American Journal of Health Promotion, 18(5), 378-386.

National Health and Morbidity Survey 2011 (NHMS 2011). Vol. II: Non-Communicable Diseases; 2011: 188 pages. Institute for Public Health (IPH) 2011.

Patton, M. Q. (2002). Qualitative research and evaluation methods. 3rd Edition. United States of America:Sage Publication, Inc.

Prins, R. G., Oenema, A., van der Host, K., \& Brug, J. (2009). Objective and perceived availability of physical activity opportunities: differences in associations with physical activity behavior among urban adolescents. International Journal of Behavioral Nutrition and Physical Activity, 6(1), 70-79. 
Pon, L. W., Kandiah, M., \& Mohd Nasir, M. T. (2004). Body image perception, dietary practices and physical activity of overweight and normal weight Malaysian female adolescents. Malaysian Journal of Nutrition, 10(2), 131-147.

Rampal, L., Rampal, S., Khor, G. L., Zain, A. M., Ooyub, S., Rahmat, R., Ghani, S. N., \& Krishnan, J. (2007). A national study on the prevalence of obesity among 16127 Malaysians. Asian Pacific Journal of Clinical Nutrition, 16(3), 561-566.

Ries, A. V., Gittelsohn, J., Voorhees, C. C., Roche, K. M., Clifton, K. J., \& Astone, N. M. (2008). The environment and urban adolescents' use of recreational facilities for physical activity: a qualitative study. American Journal of Health Promotion, 23(1), 43-50.

Ries, A. V., Voorhees, C. C., Roche, K. M., Gittelsohn, J., Yan, A. F., \& Astone, N. M. (2009). A quantitative examination of park characteristics related to park use and physical activity among urban youth. Journal of Adolescent Health, 45(3), S64-S70.

Sakinah, H., Seong-Ting, C., Rosniza, R., \& Jayah, K. P. (2012). Socio-demographic, dietary and physical activity determinants of adolescents overweight and obesity in Kelantan. Health and Environment Journal, 3(1), 44-53.

Sallis, J. F., Alcaraz, J. E., McKenzie, T. L., \& Hovell, M. F. (1999). Predictors of change in children's physical activity over 20 months. Variations by gender and level of adiposity. American Journal of Preventive Medicine, 16(3), 222-229

Sarwer, D. B., \& Dilks, R. J. (2012). Invited commentary: childhood and adolescent obesity: psychological and behavioral issues in weight loss treatment. Journal of Youth and Adolescence, 41(1), 98-104.

Shukur, F., Othman, N., \& Nawawi, A. H. (2010). The values of parks to the house residents. ajE-Bs, Asian Journal of Environment-Behaviour Studies, 1(2),85-94.

World Health Organization (2010). Global recommendations on physical activity for health. Retrieved on February 19, 2013 from http://whqlibdoc.who.int/publications/2010/9789241599979_eng.pdf

World Health Organization (2011). Obesity and overweight. Fact sheet. WHO Media centre. Retrieved on February 15, 2012 from http://www.who.int/mediacentre/factsheets/fs311/en/index.html 